\title{
Successful Diagnosis of Sacroiliac Joint Dysfunction
}

\author{
Patrick Buchanan (D) \\ Shashank Vodapally ${ }^{2}$ \\ David W Lee ${ }^{3}$ \\ Jonathan M Hagedorn (iD ${ }^{4}$ \\ Christopher Bovinet ${ }^{5}$ \\ Natalie Strand (D) ${ }^{6}$ \\ Dawood Sayed (1D ${ }^{7}$ \\ Timothy Deer $\mathbb{D}^{8}$ \\ 'Department of Pain Medicine, Spanish \\ Hills Interventional Pain Specialists, \\ Camarillo, CA, USA; ${ }^{2}$ Department of \\ Physical Medicine and Rehabilitation, \\ Michigan State University, East Lansing, MI, \\ USA; ${ }^{3}$ Department of Pain Medicine, \\ Fullerton Orthopedic Surgery Medical \\ Group, Fullerton, CA, USA; ${ }^{4}$ Department \\ of Anesthesiology and Perioperative \\ Medicine, Division of Pain Medicine, Mayo \\ Clinic, Rochester, MN, USA; ${ }^{5}$ Department \\ of Pain Medicine, The Spine Center of \\ Southeast Georgia, Brunswick, GA, USA; \\ ${ }^{6}$ Department of Anesthesiology, Division of \\ Pain Medicine, Mayo Clinic, Phoenix, AZ, \\ USA; ${ }^{7}$ Department of Anesthesiology, \\ Division of Pain Medicine, The University of \\ Kansas Medical Center, Kansas City, KS, \\ USA; ${ }^{8}$ Department of Pain Medicine, The \\ Spine and Nerve Center of the Virginias, \\ Charleston, WV, USA
}

Correspondence: Patrick Buchanan Email pbuchana@gmail.com
Background: Sacroiliac joint (SIJ) pain is one of the most common causes of low back pain, accounting for 15 to $30 \%$ of all cases. Although SIJ dysfunction accounts for a large portion of chronic low back pain prevalence, it is often overlooked or under diagnosed and subsequently under treated. The purpose of this review was to establish a best practices model to effectively diagnose SIJ pain through detailed history, physical exam, review of imaging, and diagnostic block.

Methods: A literature search was performed on the diagnosis of sacroiliac joint pain and sacroiliac joint dysfunction. The authors proposed diagnostic recommendations based upon the available literature and a detailed understanding of diagnosing SIJ pain.

Results: The practitioner must focus on the history, location of pain, observed gait pattern, and perform key points of the physical exam including sacroiliac provocative maneuvers. If the patient exhibits at least three provocative maneuvers then the SIJ may be considered as a possible source of pain. Additionally, a thorough review of the imaging should be performed to rule out other etiologies of low back pain. In the absence of any pathognomonic tests or examination findings, diagnostic SIJ blocks have evolved as the diagnostic standard. Conclusion: The diagnosis of SIJ pain is a multifaceted process that involves a careful assessment including differentiating other pain generators in the region. This involves careful history taking, appropriate physical examination including provocative maneuvers and diagnostic injections. Once the diagnosis is confirmed, long-term solutions may be considered, including recent advances in sacral lateral branch denervation and sacroiliac joint fusion.

Keywords: sacroiliac joint, SIJ, low back pain, diagnosis, best practices, review

\section{Introduction}

Low back pain is one of the most common global health problems and creates a substantial burden on society. An estimated 70 to $85 \%$ of the western population will develop low back pain at least once during their lifetime. ${ }^{1}$ Sacroiliac joint (SIJ) pain is one of the most common causes of low back pain, accounting for 15 to $30 \%$ of all cases. ${ }^{2}$ It is the most likely source of low back pain in patients after having undergone either lumbar or lumbosacral fusion surgery. ${ }^{3}$ The incidence of SIJ degeneration in patients who have undergone lumbar fusion surgery is $75 \%$ at five years post-surgery, based on radiographic imaging. ${ }^{4}$ Although SIJ dysfunction accounts for a large portion of chronic low back pain prevalence, it is often overlooked or under diagnosed and subsequently under treated.

The SIJ is a large diarthrodial joint that connects the sacrum with the ilium (iliac bone) in the posterior pelvis. It acts as a shock absorber by dissipating the vertical forces of the spine and transmits these forces to the hips and lower extremities. The SIJ becomes unstable when ligamentous laxity occurs, especially the interosseous and posterior ligaments. The primary mechanism of SIJ injury is a combination of 
axial loading and abrupt rotation. ${ }^{5}$ SIJ instability can also be a result of repetitive microtrauma.

The etiology of SIJ pain can be classified into two categories: traumatic and atraumatic. Traumatic causes often involve sudden events, such as motor vehicle accidents, falls, and lifting/twisting injuries. Atraumatic causes include infections, cumulative injury, multiple pregnancies, and inflammatory arthropathies. Risk factors that cause stress on the SIJ include gait abnormalities, ${ }^{5}$ prior lumbar fusion, ${ }^{6}$ obesity, lumbar spinal stenosis, pregnancy, ${ }^{7}$ leg length discrepancy, and scoliosis. ${ }^{8}$ Understanding the reported symptoms and physical exam findings that accompany SIJ dysfunction is imperative for any physician or health-care provider who treats patients with low back pain. With all the new advancements for durable pain relief for SIJ pain and dysfunction, accurate diagnosis is crucial to treat this growing population of undertreated patients.

\section{History and Physical Exam}

SIJ disorders are best differentiated from other forms of low back pain by using a combination of diagnostic modalities, including obtaining a thorough history and physical examination. SIJ pain typically presents as a uni- or bilateral aching pain below the L5 level without numbness or paresthesia (tingling). Patients typically report low back pain that is worse after prolonged sitting, bending forward, and with transfers out of a bed or up from a low chair or toilet. Pain in these patients may worsen after performing weight-bearing activities, such as climbing stairs, bending, twisting, or even prolonged walking. Repetitive bending with activities such as vacuuming, sweeping, mopping, pulling weeds and loading a dishwasher can also exacerbate SIJ pain. Gait is often compromised in individuals with SIJ pain. This dysfunction involves reduced coactivation of the gluteus maximus and contralateral latissimus dorsi, which together provide joint stability during walking. ${ }^{9}$

While no single physical exam maneuver is diagnostic, a combination of specific findings and provocative tests can be essential in determining SIJ disorders. Specific physical exam provocative tests for SIJ dysfunction include FABER, compression, distraction, thigh thrust, and Gaenslen tests. Typically, SIJ pain is diagnosed when at least three out of the five provocative maneuvers are positive. Of the three positive tests, either the thigh thrust or compression test should be positive. By performing these provocative maneuvers, there is an $85 \%$ pretest probability that an intra-articular joint injection will be successful. ${ }^{10}$ Another study confirmed that three or more pain provocation SIJ tests have a $91 \%$ sensitivity and $78 \%$ specificity. ${ }^{11}$

\section{SIJ Provocative Tests FABER Test (Patrick's Test)}

When performing the FABER test (Figure 1), the patient lies supine on the examination table. The examiner brings the hip joint on the ipsilateral side of SIJ pain into the FABER position. The ipsilateral knee is flexed at $90^{\circ}$ and the hip is externally rotated with the ipsilateral foot resting on the contralateral knee. Subsequently, the examiner presses the contralateral anterior superior iliac spine (ASIS) against the table and pushes the flexed knee down toward the table. The test is considered positive if the patient feels pain in the SIJ on the side where the knee was flexed. Although, some textbooks suggest the FABER test can also stress the contralateral SIJ. At this point, pain in the buttocks is suggestive of SIJ pain, whereas pain in the groin region could indicate hip pathology. When performed correctly, the FABER test can have one of the highest sensitivities of the five provocative maneuvers. ${ }^{12}$ This test is also useful in this current age of telemedicine as patients can perform their own FABER examination by sitting

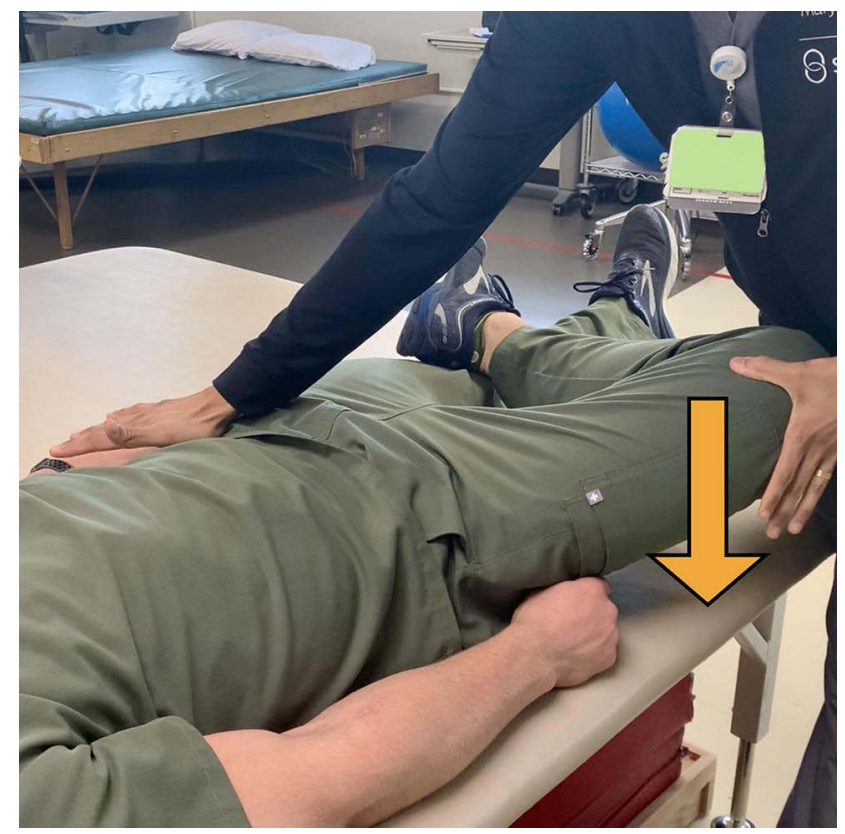

Figure I FABER Test (Patrick's Test) - With the patient in a supine position, the lower extremity ipsilateral to the patient's painful SIJ is correctly positioned by lying their lateral ankle on the contralateral anterior thigh. Then with the clinician standing on the side of the painful SIJ, one hand must stabilize the contralateral ASIS with firm pressure, while simultaneously applying a downward force through the ipsilateral flexed, externally rotated and abducted lower extremity, as depicted by the arrow. 
on a chair, and crossing the ankle of the affected side over the contralateral knee and pushing down on their ipsilateral knee while leaning back in their chair.

\section{Thigh Thrust Test (Posterior Shear Test)}

When performing the Thigh Thrust Test (Figure 2), the patient lies in a supine position while the tested-side hip joint and knee are flexed to approximately $90^{\circ}$ by the examiner. An anterior to posterior shear force is applied to the SIJ through the axis of the femur. Resulting pain at the ipsilateral SIJ indicates a positive test.

\section{Gaenslen Test}

When performing the Gaenslen Test (Figure 3), the patient is supine lying close to the side of the table, with the leg on the side to be tested hanging over the edge of the table and the other hip and knee flexed to the chest. The examiner applies firm pressure to the flexed knee, and a counter pressure is applied to the knee of the hanging leg. The procedure is then repeated on the opposite side. This places stress on bilateral SIJ. The test is considered positive if the patient feels low back pain in their SIJ during testing.

\section{Gaenslen Test (Modified Technique)}

With the patient lying in a lateral decubitus position (Figure 4), the painful SIJ is away from the table and

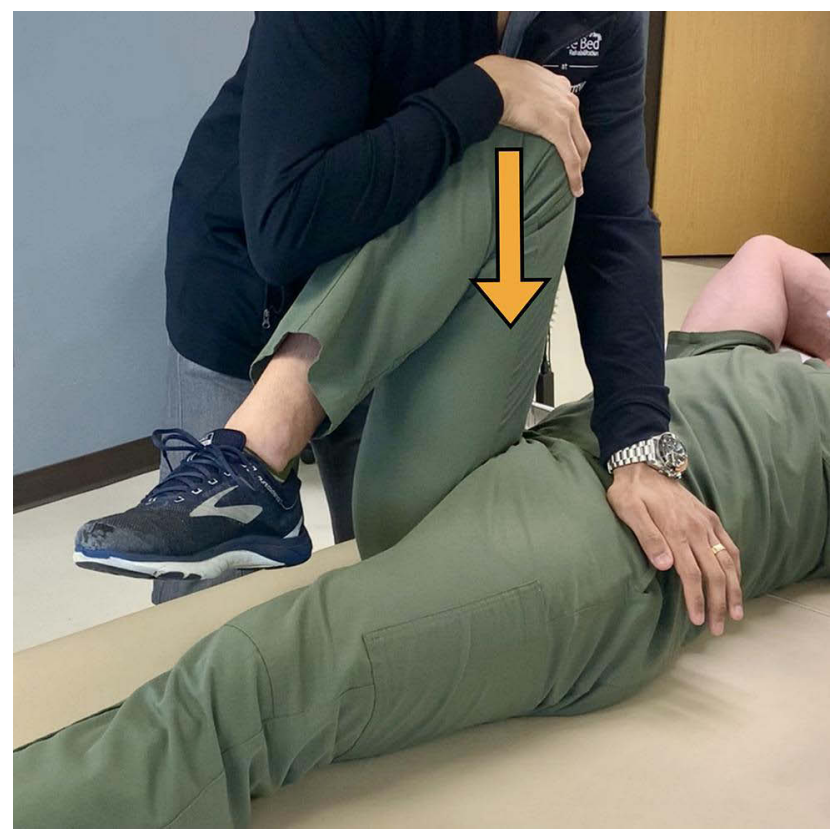

Figure 2 Thigh Thrust Test (Posterior Shear Test) - With the patient lying in a supine position the hip and knee ipsilateral to the painful SIJ are flexed, and the femur is positioned perpendicular to the table. A linear downward force through the femur towards the table is applied as depicted by the arrow.

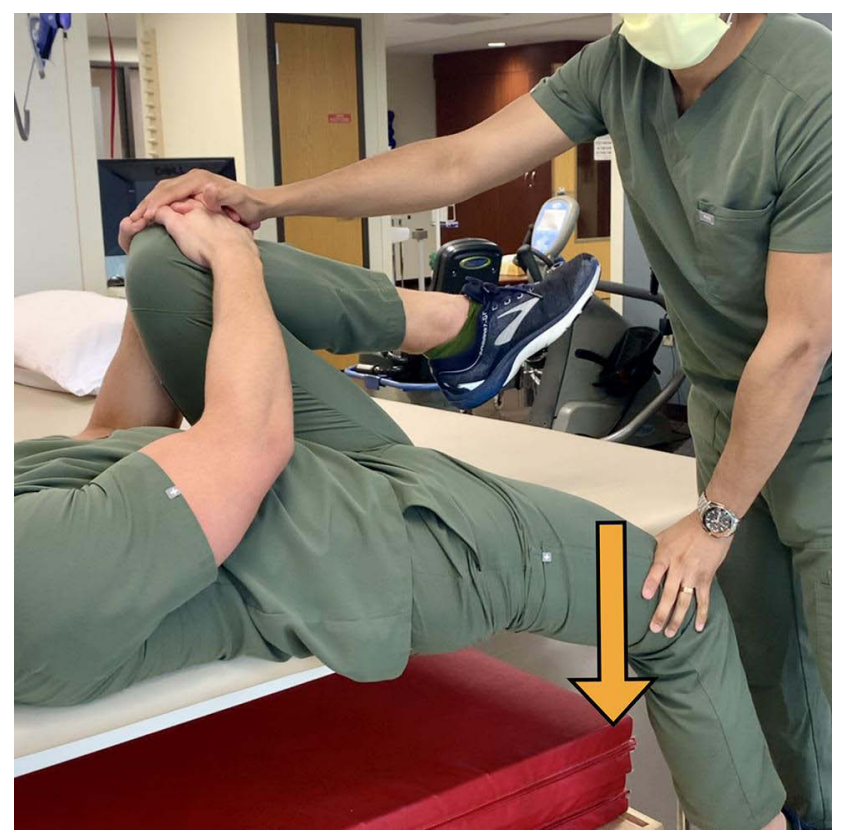

Figure 3 Gaenslen Test - While stabilizing a patient's flexed knee, a counter force depicted by the arrow is applied through the hanging leg towards the floor.

contralateral leg is flexed toward the patient's chest (similar to the traditional Gaenslen test). The examiner stands behind the patient, who is positioned at the edge of the bed. Then, stabilize the pelvis using one hand by applying a firm anterior pressure, and then extends the patient's lower extremity at the hip ipsilateral to the painful SIJ as

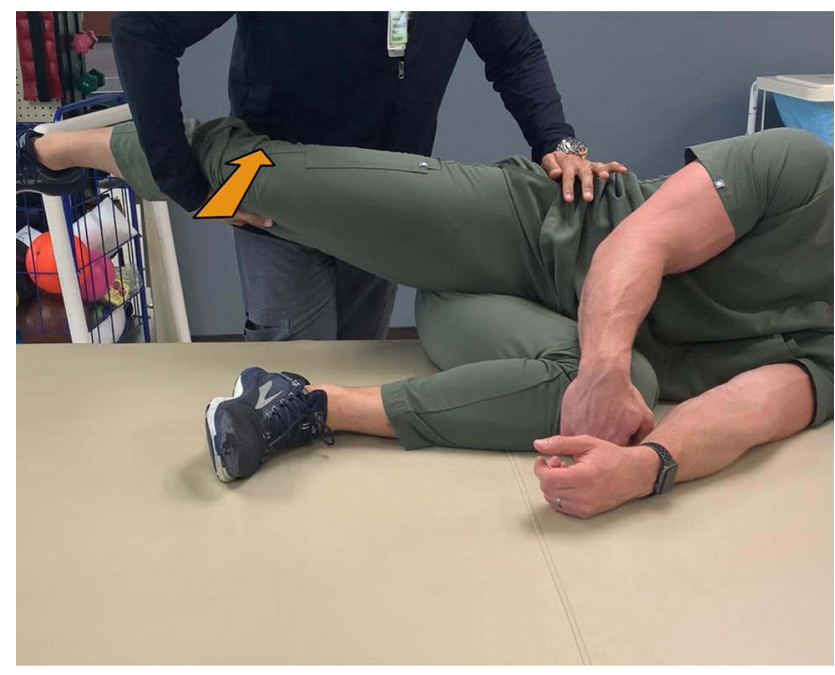

Figure 4 Gaenslen Test (modified technique) - With the patient lying in a lateral decubitus position, the painful SIJ is away from the table and contralateral leg is flexed toward the patient's chest (similar to the traditional Gaenslen test). The Examiner stands behind the patient, who is positioned at the edge of the bed. Then stabilize the pelvis using one hand by applying a firm anterior pressure, and then extends the patient's lower extremity at the hip ipsilateral to the painful SIJ as depicted by the arrow. Consider this modified test for those who are unable to lay supine. 
depicted by the arrow. Consider this modified test for those who are unable to lay supine.

\section{Compression Test}

When performing the Compression Test (Figure 5), the patient lies in the lateral decubitus position, with the affected side up, and facing away from the examiner, who applies a downward pressure to the ipsilateral iliac crest and anterior superior iliac spine (ASIS). The test is considered positive if the patient feels pain in the SIJ on the ipsilateral side.

\section{Distraction Test}

When performing the Distraction Test (Figure 6), the patient is placed supine on the table. With the patient's forearms crossed, the examiner applies slow and steady outward pressure to the left and right ASIS, spreading or distracting them apart. The test is considered positive if the patient feels pain in the SIJ area.

\section{Yeoman Test}

The patient lies in a prone position with the ipsilateral knee flexed at 90 degrees. Passively, the examiner then lifts the leg off the table, extending the hip. Pain reproduced to the sacroiliac joint indicates pathology in the anterior sacroiliac ligament, whereas anterior thigh paresthesia may indicate a femoral nerve stretch or tight

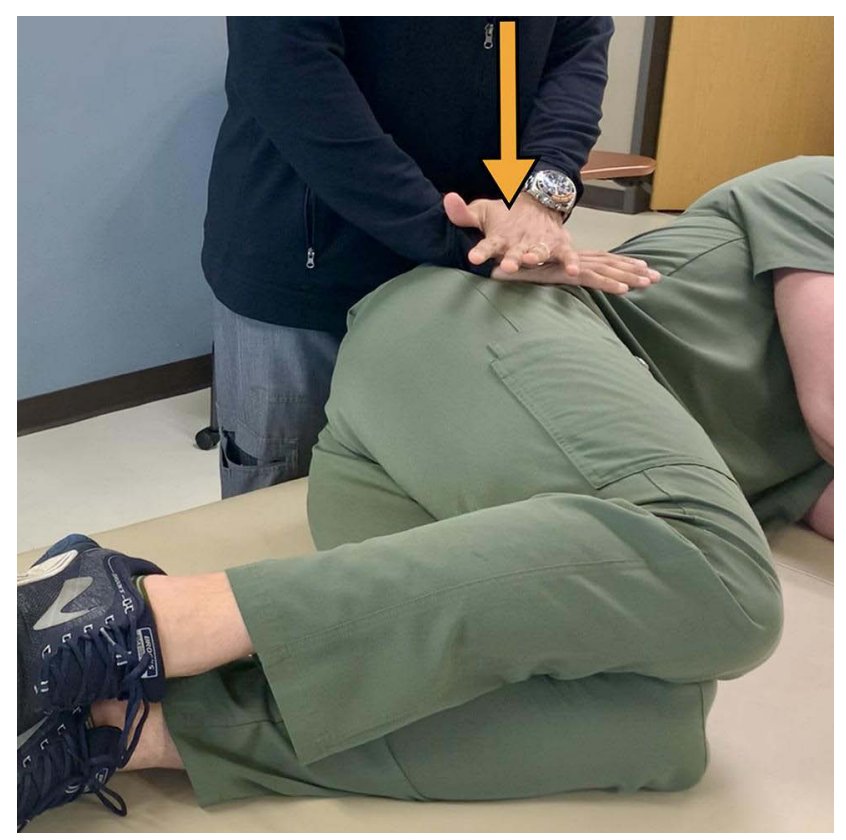

Figure 5 Compression Test - The patient is positioned in a lateral decubitus position, facing away from The Examiner, and their painful SIJ facing away from the table. While standing at the level of the pelvis, The Examiner applies a firm downward force through the ilium as seen by the arrow.

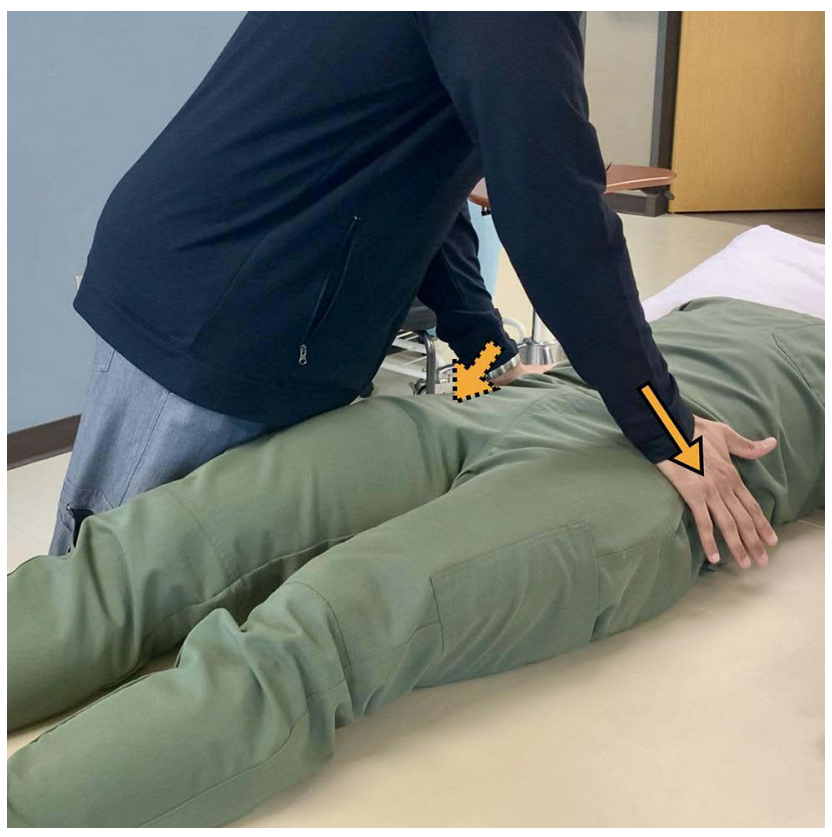

Figure 6 Distraction Test - With the patient supine, the clinician applies a downward and lateral force, away from midline, through the patient's ASIS as depicted by the two arrows.

anterior thigh musculature. One study showed sensitivity to be $64.1 \%$ and specificity to be $33.3 \%{ }^{13}$ In another study by Weksler, the authors identified positivity rates for the Yeoman test to be upwards of $80 \% .^{14}$

\section{Diagnostic Imaging}

Although helpful, but not definitive for the diagnosis of a pain generator, it is important to obtain imaging of the SIJ to rule out red flags such as fracture, malignancy, or infection. Initial imaging should include lumbar and pelvis X-ray with anterior/posterior, oblique, and lateral views. These images can help rule out other sources of LBP which may masquerade as SIJ pain, including hip osteoarthritis, lumbosacral spondylosis, and spondylolisthesis. ${ }^{15}$ The timing of imaging varies greatly on patient presentation and the presence of any "red flag" symptoms. Typically, pain that has been present for less than 6 weeks does not need to be imaged. If pain is present for longer than six weeks, imaging should be considered. In addition, if interventional therapy is planned, plain films should be obtained prior to injection. MRI of the lumbar spine to rule out neural compression, especially of the L5 nerve root may be helpful. The SIJ can be difficult to profile on radiographs, and clear evidence of structural lesions involving the joint may or may not be identifiable. Magnetic resonance imaging 
(MRI) is often recommended for the diagnosis of sacroiliitis related to HLA-B27 seronegative spondyloarthropathies (Psoriasis arthritis, Ankylosing spondylitis, Inflammatory bowel disease with associated arthritis, and Reactive arthritis) due to its high sensitivity and ability to visualize bone marrow and SIJ edema (Figure 7). ${ }^{16}$ SIJ pain due to non-inflammatory arthropathy typically has little findings on advanced imaging, but can show joint space narrowing, osteophytes and sclerosis (Figure 8).

\section{Diagnostic Injection}

It can be challenging to make an exact diagnosis of SIJ pain due to the fact that there is no pathognomonic clinical history, physical examination, or radiological evidence for SIJ dysfunction. Furthermore, symptoms may be the result of other common spinal conditions, such as lumbosacral facet syndrome, disc herniation, or proximal L5 nerve pathology. With no evidence to support any single provocative SIJ maneuver or diagnostic imaging modality as pathognomonic for SIJ pain, intra-articular SIJ blocks utilizing local anesthetics with or without steroids have evolved as the diagnostic standard. ${ }^{17}$

Historically, SIJ injections were performed without image guidance and based solely on palpation techniques. In a single-site study, blind SIJ injections were initially performed and then needle placement was confirmed with fluoroscopy. Accurate placement of SIJ injection was found to be successful in only $12 \%$ of injections when performed blind. ${ }^{18}$ Fluoroscopic guidance has been shown to be more accurate than ultrasound guided (98.2\% vs $87.3 \%)$, although both means are reliable methods of infiltrating the SIJ. ${ }^{19}$ The main limitation with ultrasound-guided SIJ injections is the lack of ability to visualize an arthrogram as one would on fluoroscopy. CT-guided injections have also been identified to allow for intra-articular injections with reduction in SIJ pain symptoms. However, one study showed accurate needle placement in only $76 \%$ of cases. ${ }^{20}$ A recent single-site study suggested improved efficacy with CT-guided versus fluoroscopically guided injections in the SIJ. However, limitations and drawbacks of CT-guided SIJ injections include the lack of ability to view contrast in real-time both intra-articularly, as well as contrast extravasation, and the risk of increased radiation exposure. ${ }^{21}$
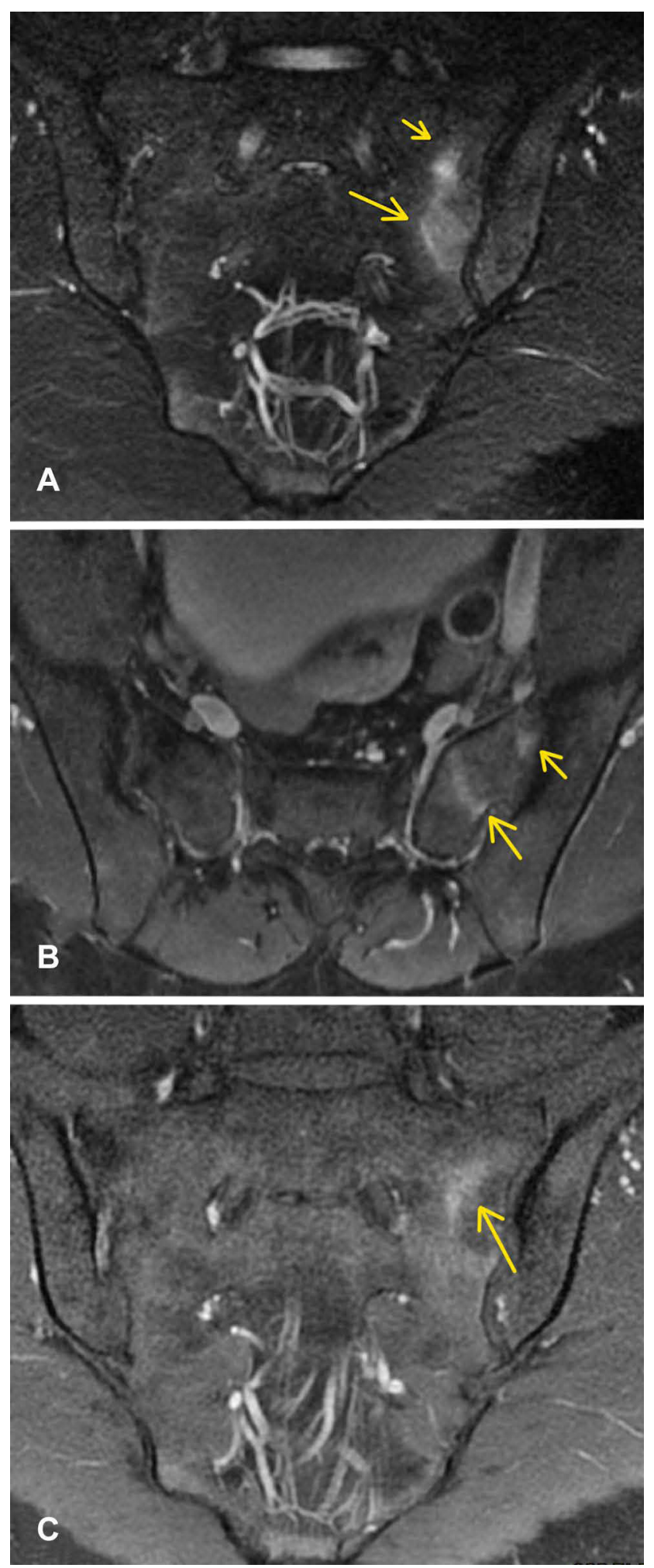

Figure 7 (A) Coronal view sacral T2 MRI with enhancement depicted by yellow arrows. (B and C) Axial and coronal view TI MRI, respectively, showing post contrast enhancement depicted by yellow arrows. When these findings are seen concurrently in a patient, it is representative of bone marrow edema, which can be a sign of sacroiliitis. 


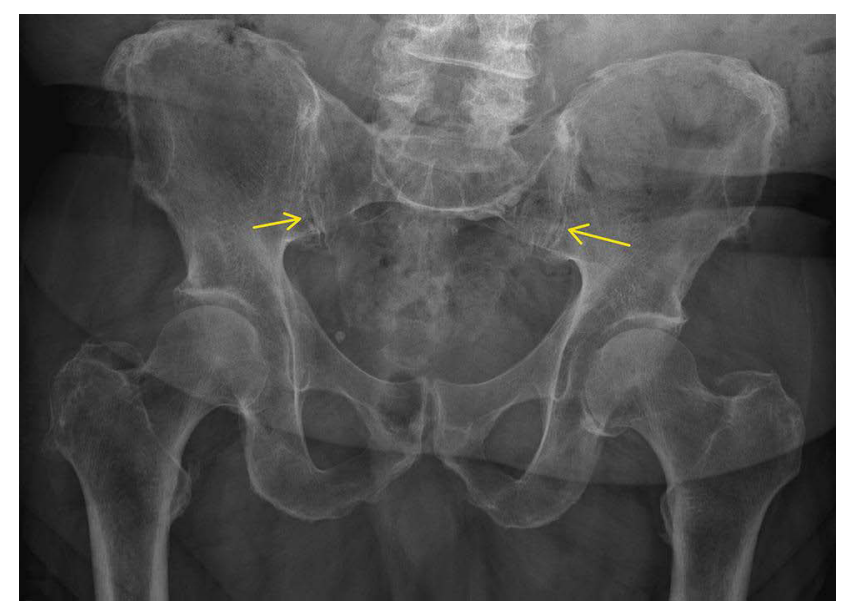

Figure 8 Anterior-posterior radiograph of pelvis showing joint space narrowing, some subcortical sclerotic changes (yellow arrows), anterior sacral osteophyte formation, and joint surface irregularity which is seen in osteoarthritis of the SIJ.

Based on the qualitative evidence, the diagnostic accuracy is at Level II for dual diagnostic blocks with at least $70 \%$ pain relief and Level III for single diagnostic blocks with at least $75 \%$ pain relief. The recommended volume of injectate ranges from 1 to $2 \mathrm{~mL}^{22,23}$ Certain guidelines recommend single-injection diagnostic block for clinical studies $^{24}$ while others suggest double (confirmatory) diagnostic blocks more accurately determine the source of pain by using two different local anesthetics with different durations of action. ${ }^{25,26}$ The International Association for the Study of Pain (IASP) criteria for diagnosis of SIJ dysfunction includes pain in the area of the SIJ, reproducible with provocative maneuvers, and must be relieved with local anesthetic injection into the SIJ or to the lateral branch nerves. ${ }^{27}$

Diagnostic blocks may be assessed in a similar manner to that of the medial branch blocks. The relief from a diagnostic block should be immediately assessed after the procedure is performed. Additionally, in the most rigorous diagnostic criteria, the relief from a sacroiliac joint block should coincide with the duration of anesthetic utilized. Utilization of a pain log can be helpful in tracking the pain score to better accurately assess the patient's experience. Reduction of pain greater than $50 \%$ had been historically used as the diagnostic cutoff for a sacroiliac joint block. More recently $75 \%$ has been recommended, and use of dual diagnostic blocks prior to therapeutic sacroiliac joint treatment.

A posterior approach to the SI joint injection has been widely accepted. The patient is placed in a prone position. The fluoroscope is typically positioned in a contralateral oblique orientation (at approximately
20-35 degrees depending on pelvic anatomy) to line up the anterior and posterior SIJ line. The typical target utilized for an SIJ injection is the most inferior aspect of the joint (Figure 9), although a superior and middle joint approach (Figure 10) has been described. ${ }^{28,29}$ A 22 or 25-gauge needle with a stylet is most commonly used in this approach. A quantity range of $0.2-0.5 \mathrm{~mL}$ contrast medium (when utilizing fluoroscopic guidance) has been described to confirm the proper needle placement that is intra-articular and extra-vascular and is essential regardless of the SIJ entrance site. ${ }^{30-33}$ Alternatively, if unable to utilize contrast dye due to a reported allergy or kidney disease, biplanar fluoroscopy with contralateral oblique and lateral views can be utilized to confirm appropriate needle tip placement within the joint.

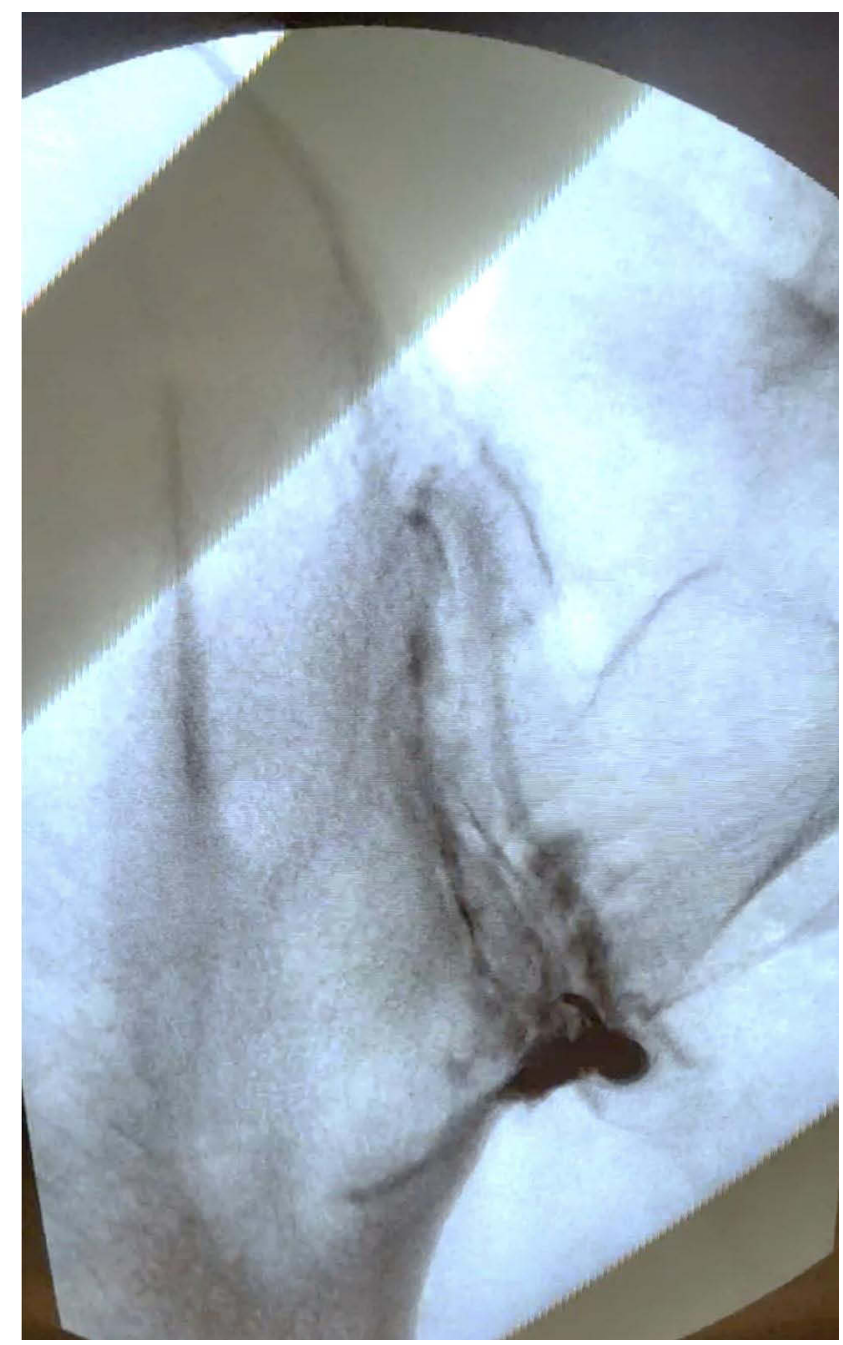

Figure 9 A fluoroscopic guided intra-articular SIJ injection utilizing the inferior joint approach. The fluoroscope is placed in contralateral oblique positioning. Typically oblique positioning is between 5 and 15 degrees, until the anterior and posterior sacroiliac joint lines intersect at the most inferior aspect of the joint. 


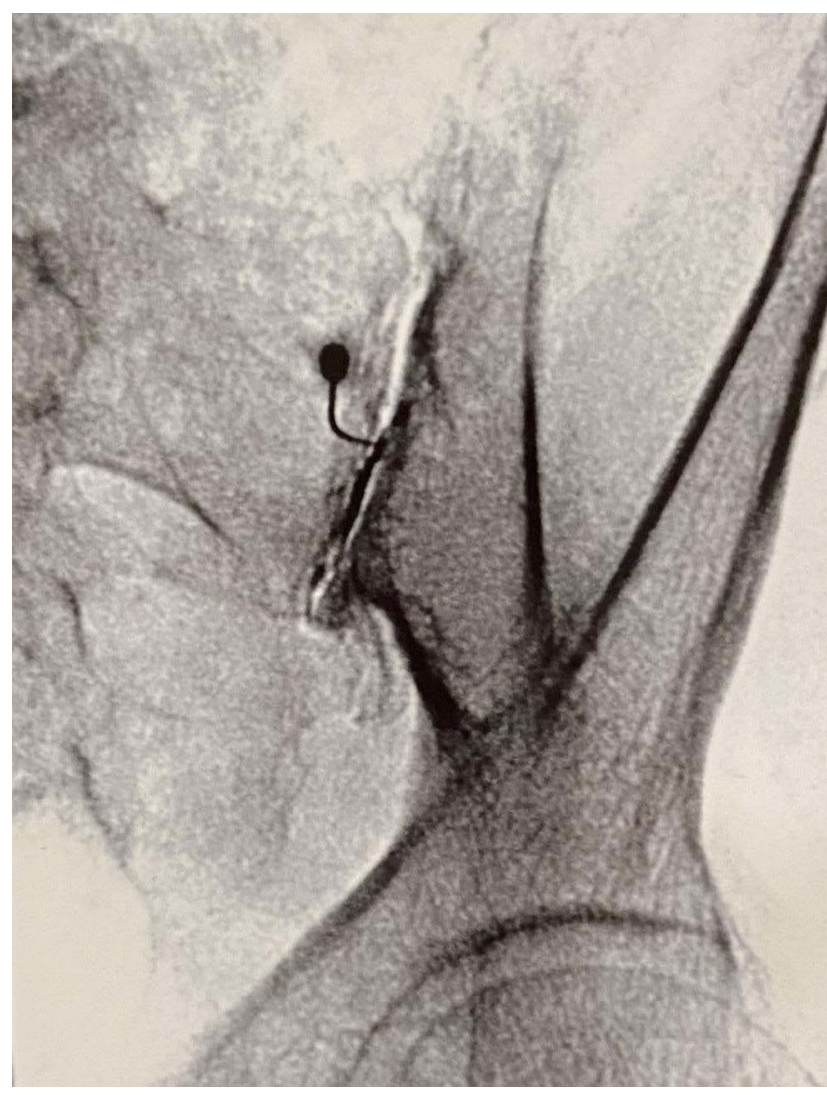

Figure 10 A fluoroscopic guided intra-articular SIJ injection utilizing a mid-body entrance. The fluoroscope is placed in contralateral oblique positioning. Compared to the inferior joint approach, cranial tilt and a great degree of obliquity is required. The obliquity is performed until the anterior and posterior sacroiliac joint lines intersect at the midbody of the joint.

Histological analysis of the sacroiliac joint has verified the presence of nerve fibers within the joint capsule and adjoining ligaments. ${ }^{34}$ The sacroiliac joint receives its innervation from the ventral rami of L4 and L5, the superior gluteal nerve and the dorsal rami of L5, S1, and S2. Sacral lateral branch nerve blocks have been more recently utilized in part to address pain from the posterior sacroiliac structures, which includes both the posterior joint itself as well as the various ligaments. There is, however, additional ventral innervation of the sacroiliac joint that is typically inaccessible for blocks or denervation. As a result, the use of sacral lateral branch nerve blocks is exclusively used to prognosticate response to radiofrequency neurotomy, and not diagnostic for sacroiliac joint dysfunction. There is no available literature that evaluates its ability to be used as a screening test for more definitive surgical procedures such as sacroiliac fusion. ${ }^{35}$

\section{Differential Diagnosis}

When patients report posterior hip or low back pain below the level L5 or the beltline, various causes other than sacroiliitis should be considered, including seronegative spondyloarthropathies, posterior femoro-acetabular pathology, proximal hamstring tendinopathy, piriformis syndrome, stress fracture of the sacrum, and referred pain from lumbar spinal pathology including lumbosacral facetmediated pain and proximal L5 radiculopathy. Although there are some overlapping characteristics amongst these other diagnoses, the following list helps to correlate various differentials with their particular findings. ${ }^{36-38}$

1. Localization of pain to the spine or radiating pain into the lower extremities with a positive straight leg raise may suggest a spinal or spinal nerve pathology.

2. Concomitant anterior and posterior hip pain with a FABER test producing pain localizing in the groin area may point towards femoro-acetabular pathology.

3. Tenderness to palpation over the body of the piriformis muscle with a positive FADIR (Hip flexion, adduction, and internal rotation) test may suggest piriformis syndrome.

4. Perineal pain worsened with palpation over the ischial spine may point toward a pudendal neuropathy.

5. Patients with reproducible pain along with the proximal hamstring muscle or tendon through various active, passive and resisted range of motion may have a hamstring strain, rupture, or tendinopathy.

6. Axial low back pain that is worse with lumbar extension and positive for lumbar facet loading may be indicative of lumbar facet arthropathy.

7. Pain localized over the inferior sacrum and coccygeal region may represent sacrocoxalgia or coccydynia.

Understanding the relationship between these various findings and correlated pathologies is crucial to identifying and appropriately addressing a patient's source of low back and posterior hip pain. It is not uncommon for SIJ pain to present concomitantly with some of these other underlying pathologies and having them in your differential will help formulate an appropriate treatment plan for the patient.

\section{Conclusion}

The diagnosis of SIJ pain is a multifaceted process that involves a careful assessment. The practitioner must first focus on the history, observe the gait pattern, and perform the key points of the physical exam including provocative 
maneuvers. A thorough review of the imaging should be performed. SIJ diagnostic blocks will confirm the diagnosis. It is essential to rule out other concomitant pathologies. Once the diagnosis is confirmed, long-term solutions may exist, such as SIJ ablation, or posterior or lateral SIJ fusion. In addition, long-term spinal comorbidities often accompany SIJ dysfunction and should be reassessed frequently in those who suffer from other pain pathologies.

\section{Funding}

There is no funding to report.

\section{Disclosure}

PB is a consultant for Abbott and PainTEQ. JMH is a consultant for Abbott, Boston Scientific, and Nevro. $\mathrm{CB}$ is a consultant for Nevro, Boston Scientific, Vertiflex, and PainTEQ. TD is a consultant for Abbott, Nalu, SPR, Saluda, PainTeq, Cornorloc, Vertiflex, Spinethera. Funded Research, Vertiflex (Boston Scientific), Abbott, Saluda, SPR. DS is a consultant for Abbott, Medtronic, Merit, Nevro, Painteq, SPR, and Vertos. NS is a consultant for Abbott and Nevro. The authors report no other conflicts of interest in this work.

\section{References}

1. Andersson GB. Epidemiological features of chronic low-back pain. Lancet. 1999;354(9178):581-585. doi:10.1016/S0140-6736(99)01312-4

2. Cohen SP, Chen Y, Neufeld NJ. Sacroiliac joint pain: a comprehensive review of epidemiology, diagnosis and treatment. Expert Rev Neurother. 2013;13(1):99-116. doi:10.1586/ern.12.148

3. DePalma MJ, Ketchum JM, Saullo TR. Etiology of chronic low back pain in patients having undergone lumbar fusion. Pain Med. 2011;12 (5):732-739. doi:10.1111/j.1526-4637.2011.01098.x

4. Ha KY, Lee JS, Kim KW. Degeneration of sacroiliac joint after instrumented lumbar or lumbosacral fusion: a prospective cohort study over five-year follow-up. Spine. 2008;33(11):1192-1198. doi:10.1097/BRS.0b013e318170fd35

5. Kiapour A, Joukar A, Elgafy H, Erbulut DU, Agarwal AK, Goel VK. Biomechanics of the sacroiliac joint: anatomy, function, biomechanics, sexual dimorphism, and causes of pain. Int J Spine Surg. 2020;14 (Suppl1):3-13. doi:10.14444/6077

6. Katz V, Schofferman J, Reynolds J. The sacroiliac joint: a potential cause of pain after lumbar fusion to the sacrum. $J$ Spinal Disord Tech. 2003;16(1):96-99. doi:10.1097/00024720-200302000-00015

7. Albert H, Godskesen M, Westergaard J. Prognosis in four syndromes of pregnancy-related pelvic pain. Acta Obstet Gynecol Scand. 2001;80 (6):505-510.

8. Schuit D, McPoil TG, Mulesa P. Incidence of sacroiliac joint malalignment in leg length discrepancies. J Am Podiatr Med Assoc. 1989;79 (8):380-383. doi:10.7547/87507315-79-8-380

9. Feeney DF, Capobianco RA, Montgomery JR, Morreale J, Grabowski AM, Enoka RM. Individuals with sacroiliac joint dysfunction display asymmetrical gait and a depressed synergy between muscles providing sacroiliac joint force closure when walking. $J \quad$ Electromyogr Kinesiol. 2018;43:95-103. doi:10.1016/j. jelekin.2018.09.009
10. Szadek KM, van der Wurff P, van Tulder MW, Zuurmond WW, Perez RS. Diagnostic validity of criteria for sacroiliac joint pain: a systematic review. J Pain. 2009;10(4):354-368. doi:10.1016/j. jpain.2008.09.014

11. Laslett M, Young SB, Aprill CN, McDonald B. Diagnosing painful sacroiliac joints: a validity study of a McKenzie evaluation and sacroiliac provocation tests. Aust J Physiother. 2003;49(2):89-97. doi:10.1016/s0004-9514(14)60125-2

12. Telli H, Telli S, Topal M. The validity and reliability of provocation tests in the diagnosis of sacroiliac joint dysfunction. Pain Physician. 2018;21(4):E367-E376. doi:10.36076/ppj.2018.4.E367

13. Nejati P, Sartaj E, Imani F, Moeineddin R, Nejati L, Safavi M. Accuracy of the diagnostic tests of sacroiliac joint dysfunction. J Chiropr Med. 2020;19(1):28-37. doi:10.1016/j.jcm.2019.12.002

14. Weksler N, Velan GJ, Semionov M, et al. The role of sacroiliac joint dysfunction in the genesis of low back pain: the obvious is not always right. Arch Orthop Trauma Surg. 2007;127(10):885-888. doi:10.1007/s00402-007-0420-x

15. Barros G, McGrath L, Gelfenbeyn M. Sacroiliac joint dysfunction in patients with low back pain. Fed Pract. 2019;36(8):370-375.

16. Diekhoff T, Hermann KG, Greese J, et al. Comparison of MRI with radiography for detecting structural lesions of the sacroiliac joint using CT as standard of reference: results from the SIMACT study. Ann Rheum Dis. 2017;76(9):1502-1508. doi:10.1136/annrheumdis2016-210640

17. Jung MW, Schellhas K, Johnson B. Use of diagnostic injections to evaluate sacroiliac joint pain. Int $J$ Spine Surg. 2020;14 (Suppl1):30-34. doi:10.14444/6081

18. Hansen HC. Is fluoroscopy necessary for sacroiliac joint injections? Pain Physician. 2003;6(2):155-158. doi:10.36076/ppj.2003/6/155

19. Jee H, Lee JH, Park KD, Ahn J, Park Y. Ultrasound-guided versus fluoroscopy-guided sacroiliac joint intra-articular injections in the noninflammatory sacroiliac joint dysfunction: a prospective, randomized, single-blinded study. Arch Phys Med Rehabil. 2014;95 (2):330-337. doi:10.1016/j.apmr.2013.09.021

20. Althoff CE, Bollow M, Feist E, et al. CT-guided corticosteroid injection of the sacroiliac joints: quality assurance and standardized prospective evaluation of long-term effectiveness over six months. Clin Rheumatol. 2015;34(6):1079-1084. doi:10.1007/s10067-0152937-7

21. Bessar AAA, Arnaout MM, Basha MAA, Shaker SE, Elsayed AE, Bessar MA. Computed tomography versus fluoroscopic guided-sacroiliac joint injection: a prospective comparative study. Insights Imaging. 2021;12(1):38. doi:10.1186/s13244-021-00982-y

22. Simopoulos TT, Manchikanti L, Gupta S, et al. Systematic review of the diagnostic accuracy and therapeutic effectiveness of sacroiliac joint interventions. Pain Physician. 2015;18(5):E713-E756. doi:10.36076/ppj.2015/18/E713

23. Manchikanti L, Falco FJ, Benyamin RM, Kaye AD, Boswell MV, Hirsch JA. A modified approach to grading of evidence. Pain Physician. 2014;17(3):E319-E325. doi:10.36076/ppj.2014/17/E319

24. Bogduk N. Practice Guidelines for Spinal Diagnostic and Treatment Procedures; International Spine Intervention Society, San Francisco, CA. 2013

25. Fortin JD, Kissling RO, O'Connor BL, Vilensky JA. Sacroiliac joint innervation and pain. Am J Orthop. 1999;28(12):687-690.

26. Grob KR, Neuhuber WL, Kissling RO. Die Innervation des sacroiliacalgelenkes beim menschen [Innervation of the sacroiliac joint of the human]. Z Rheumatol. 1995;54(2):117-122.

27. Treede RD. The international association for the study of pain definition of pain: as valid in 2018 as in 1979, but in need of regularly updated footnotes. Pain Rep. 2018;3(2):e643. doi:10.1097/ PR9.0000000000000643

28. Kasliwal PJ, Kasliwal S. Fluoroscopy-guided sacroiliac joint injection: description of a modified technique. Pain Physician. 2016;19 (2):E329-E338. doi:10.36076/ppj/2016.19.E329 
29. Kurosawa D, Murakami E, Aizawa T. Fluoroscopy-guided sacroiliac intraarticular injection via the middle portion of the joint. Pain Med. 2017;18(9):1642-1648. doi:10.1093/pm/pnw297

30. Nacey NC, Patrie JT, Fox MG. Fluoroscopically guided sacroiliac joint injections: comparison of the effects of intraarticular and periarticular injections on immediate and short-term pain relief. AJR Am $J$ Roentgenol. 2016;207(5):1055-1061. doi:10.2214/AJR.15.15779

31. Liliang PC, Liang CL, Lu K, Weng HC, Syu FK. Modified fluoroscopy-guided sacroiliac joint injection: a technical report. Pain Med. 2014;15(9):1477-1480. doi:10.1111/pme.12492

32. Kennedy DJ, Engel A, Kreiner DS, Nampiaparampil D, Duszynski B, MacVicar J. Fluoroscopically guided diagnostic and therapeutic intra-articular sacroiliac joint injections: a systematic review. Pain Med. 2015;16(8):1500-1518. doi:10.1111/pme.12833

33. Wu L, Tafti D, Varacallo M. Sacroiliac joint injection]. In: StatPearls [Internet]. Treasure Island (FL): StatPearls Publishing; January, 2021. Available from: https://www.ncbi.nlm.nih.gov/books/ NBK513245/. Accessed September 30, 2021.
34. Vleeming A, Schuenke MD, Masi AT, Carreiro JE, Danneels L, Willard FH. The sacroiliac joint: an overview of its anatomy, function and potential clinical implications. J Anat. 2012;221(6):537-567. doi:10.1111/j.1469-7580.2012.01564.x

35. Cohen SP, Abdi S. Lateral branch blocks as a treatment for sacroiliac joint pain: a pilot study. Reg Anesth Pain Med. 2003;28(2):113-119. doi:10.1053/rapm.2003.50029

36. Frank RM, Slabaugh MA, Grumet RC, Virkus WW, Bush-Joseph CA, Nho SJ. Posterior hip pain in an athletic population: differential diagnosis and treatment options. Sports Health. 2010;2(3):237-246. doi: $10.1177 / 1941738110366000$

37. Tibor LM, Sekiya JK. Differential diagnosis of pain around the hip joint. Arthroscopy. 2008;24(12):1407-1421. doi:10.1016/j. arthro.2008.06.019

38. Battaglia PJ, D’Angelo K, Kettner NW. Posterior, lateral, and anterior hip pain due to musculoskeletal origin: a narrative literature review of history, physical examination, and diagnostic imaging. $J$ Chiropr Med. 2016;15(4):281-293. doi:10.1016/j.jcm.2016.08.004

\section{Publish your work in this journal}

The Journal of Pain Research is an international, peer reviewed, open access, online journal that welcomes laboratory and clinical findings in the fields of pain research and the prevention and management of pain. Original research, reviews, symposium reports, hypothesis formation and commentaries are all considered for publication. The manuscript management system is completely online and includes a very quick and fair peer-review system, which is all easy to use. Visit http:// www.dovepress.com/testimonials.php to read real quotes from published authors. 